\title{
Green Enzyme Enhanced Oil Recovery
}

\author{
Zhengwen Zeng* \\ Department of Petroleum Engineering, University of Texas Permian Basin, Midland, Texas 79705 USA
}

*Corresponding author: Zhengwen Zeng, Department of Petroleum Engineering, University of Texas Permian Basin, Midland, USA, Email: zeng_z@utpb.edu.
Received Date: June 10, 2021

Published Date: June 21, 2021

\begin{abstract}
Enhanced oil recovery (EOR) is widely performed in oil fields after primary and secondary productions. Enzyme enhanced oil recovery (EEOR) has seen rapid growth in both lab research and field applications in recent years due to its promising effectiveness and minimum footprint to the environment in comparing to other EOR methods. To promote the progress of this emerging technology, this preliminary review is conducted with the intention of revealing and sharing experience from many unpublished case studies, and integrating them with results in conference and peer reviewed papers, with special attention to the application of green enzyme, a DNA-modified protein. The collected literature and technical reports included cases from Asia, Middle East, South America and USA. Mechanisms to the success of some cases are discussed. Factors limiting the applications in some cases are shared. Directions of future efforts are proposed.
\end{abstract}

Keywords: Enhanced oil recovery; Enzyme; Wettability alternation; Interfacial tension reduction; DNA-modification

\section{Introduction}

Enhanced oil recovery (EOR) is oil production by the injection of materials not normally present in petroleum reservoirs [1]. This definition covers all modes of oil recovery processes (drive, pushpull, and well treatments) and many oil recovery agents. An oil reservoir's life can be divided into three phases: primary, secondary and tertiary. In primary phase, oil is produced by consuming natural energy: solution gas expansion, water influx drive, gas-cap drive, or gravitational drainage. In secondary phase production, oil is produced by using such techniques as gas or water injection/ flooding. The main purpose of the injections is to boost or maintain reservoir pressure; physical power (pressure) is the main force to produce the extra oil. Tertiary phase recovery is any technique applied after secondary recovery, mainly including: (1) various chemical flooding (miscible/immiscible flue/lean gas, $\mathrm{CO}_{2}$ foam, polymer, surfactant-polymer, alkaline, alkaline-polymer, alkalinesurfactant, alkaline-surfactant-polymer, etc.), (2) thermal recovery, and (3) organic/micro-organic and microbial EOR (MEOR) processes [2-4]. In chemical flooding processes, chemical changes, such as reduction of interfacial tension, alternation of wettability, reduction of viscosity, breakage of long molecule chains, etc., play major roles. In thermal recovery, both physical and chemical factors are working jointly. In MEOR processes, some reservoir components (crude oil, in-situ or injected nutrients, etc.) are consumed by the microbes/organisms, and the products could increase reservoir pressures, reduce viscosities, breaking the long molecular chains, among other mechanisms [5].

Enzyme enhanced oil recovery (EEOR) refers to any enhanced oil recovery technologies that involves using enzyme(s). Comparing to the lab studies and field pilot tests of regular EOR methods aforementioned, EEOR is an emerging technology that has limited peer reviewed papers [6-12], yet huge amount of conference papers $[22,26,30]$, and unpublished technical reports and case studies $[24,31]$. Encouraged by the promising field performance, the rich data of industrial reports, and the potential of minimum footprints, the objective of this paper is to present a preliminary review on EEOR, with special attention to the application of green enzyme 
$\left(\right.$ GreenZyme $\left.^{\mathrm{TM}}\right)$ [13].

\section{Background}

In an oil well's youth stages, few artificial forces need to be applied for efficient extraction to occur. The initial production period of a well usually makes use of the reservoir formations' intrinsic pressure to push the oil, gas and water up to the production tubing and to the surface. This is commonly referred to as the primary stage of recovery. After the reservoir becomes partially depleted to the point where natural power alone is not a sufficient driving force for production, extra energy, such as mechanical forces, must be added to generate the pressure differential between the far field of the reservoir and the near wellbore region for further oil production, and the secondary oil recovery phase begins [14].

The secondary phase of oil recovery uses an artificial driving force to increase recovery via methods such as recycled natural gas injection, water injection, $\mathrm{CO}_{2}$ injection and electric submersible pumps (ESPs) [15]. Characteristics of the well's production, lithological data of the reservoir, and properties of the fluids in the formation are used to screen for the most viable EOR methods [16]. Estimates of recovery by secondary phase practices are anywhere between $15-25 \%$ of the formations technically recoverable reserves. Globally overall recovery factor combining primary and secondary production ranges anywhere between 35- 45\% [17].

Some inconsistencies exist with the interpretation of gas $\left(\mathrm{CO}_{2}\right)$ injection as being either part of secondary or tertiary production among people in the industry and literature. Usually the secondary phase use of $\mathrm{CO}_{2}$ focuses on increasing formation pressure. In contrast, with tertiary EOR injection, $\mathrm{CO}_{2}$ is used more for viscosity reduction of hydrocarbon fluids as well as to increase the porosity and flow potential within the reservoir's geology [18]. The practices often differ in their scope and methods of implementation.

Tertiary phase or enhanced oil recovery phase starts after secondary recovery methods are no longer economically viable. Tertiary EOR methods commonly consist of thermal or chemical means for viscosity reduction and interfacial tension reduction. Some estimates assert that EOR can account for a remaining 5-15\% of the oil not extracted by the previous phases [19]. Recovery factors (RFs) depend on the specific nature of the reservoir and the extraction techniques employed. Often the well is in its older stages when these methods are employed. Thermal means of EOR commonly use injected steam or in-situ oil burning to reduce viscosity and increase pressure. Chemical means commonly include the injection of polymers, surfactants, alkaline, and their by-products, and paraffin control additives. These methods are often costly, hazardous and are subject to environmental concerns. Enzyme enhanced oil recovery, on the other hand, is a less common but promising practice that is growing in interest in the industry, due to its proven effectiveness in some cases and minimum footprints to the environment [20-21].

\section{EEOR Research and Developments}

Enzymes are naturally produced protein macromolecules that serve as mechanistic catalysts for the breakdown of specific chemical substrates. Enzymes are produced by living organisms as necessary biological machines for nearly all cellular functions. The practicality of using enzyme in oil and gas is in its infancy, but numerous studies and industrial uses for enzymes have been purported to be successful [6, 20-21]. Wettability modification is shown to be the most significant mechanism of EEOR, but paraffin breakup, paraffin buildup reduction, desulfurization [22], acid production, deep formation gel recovery/cleaning, calcium carbonate precipitation [23], and $\mathrm{CO}_{2}$ production are proposed as other beneficial factors. Enzymes show some positive effect in cleanup of oil sludge and the separation of suspended sediments. Enzymatic delivery of scale inhibitors is also of future consideration. Enzymes have been used for the catalytic degradation of gels and polymers from other chemical EOR treatments in many years [22]. But comparing to the application of other EOR technologies, EEOR hasn't been of large significance, partly due to the lack of public awareness of the lab and field results.

Wettability modification is mediated by the reduction in interfacial tension between the oil phase, water phase and the reservoir's rock formation. This is commonly achieved by creating a depression in the contact angle of adhesion of oil droplets to the solid rock surfaces. EEOR mechanisms also allow the oil to form smaller droplets so as to flow through the narrow porous media more readily. To some degree, enzymes offer a similar mechanism to the common polymer and surfactant chemical treatments. Experiments have shown changes in rock surface wettability and a reduction in oil adhesion while apparently showing increased adhesion by water. But interfacial tension reduction between oil and water phases also occurs. This creates an improved channeling effect of oil across the now water-wetting rock surfaces. Enzymes possess a broad range of chemical moieties that make them likely to exhibit adsorptive properties to the surface of calcite and other minerals. This is proposed to be one mechanism by which wettability is altered, although further investigation is needed.

Specificity of enzymes is considered as another key mechanism for the success of EEOR. In other words, the biological function of the enzymes is also important in application of EEOR when the desired effect is related to a chemical catalysis reaction. In addition to the fact that they are normally used as a good interfacial tension modifier, there have been detectable difference in the effectiveness of EEOR among the different quaternary and tertiary structures of different enzymes involved. The difference in calcite precipitation and formation adhesion also shows a well quantifiable difference when comparing lipases, carbohydrases, proteases and oxidoreductases in situ. Each of these categories describe the biological function of the enzymes, which is mediated by their general structural configuration. Khusainova and his collaborators conducted a very comprehensive study on the specifics of enzyme wettability 
modification and how it pertains to these class of enzymes [9]. This is a crucial step in the understanding and further implementation of EEOR technology. They characterized the differences in adhesion strength between these differing enzyme classes.

Wettability is often measured in terms of the contact angle between droplets of a fluid, and its adhesion to surfaces of the rock and other chemical phases. Figure 1 is an image taken from reference [9] to illustrate this concept. Many factors are contributing to the difference in performance. These could include the rock (mineral) properties, the categories and chemistry of the enzymes, and their corresponding concentrations. As shown in Figure 2, preliminary lab study of different combinations of these factors result in enhanced adhesion, temporary adhesion, and nonadhesion [9] (Figures 1\&2).

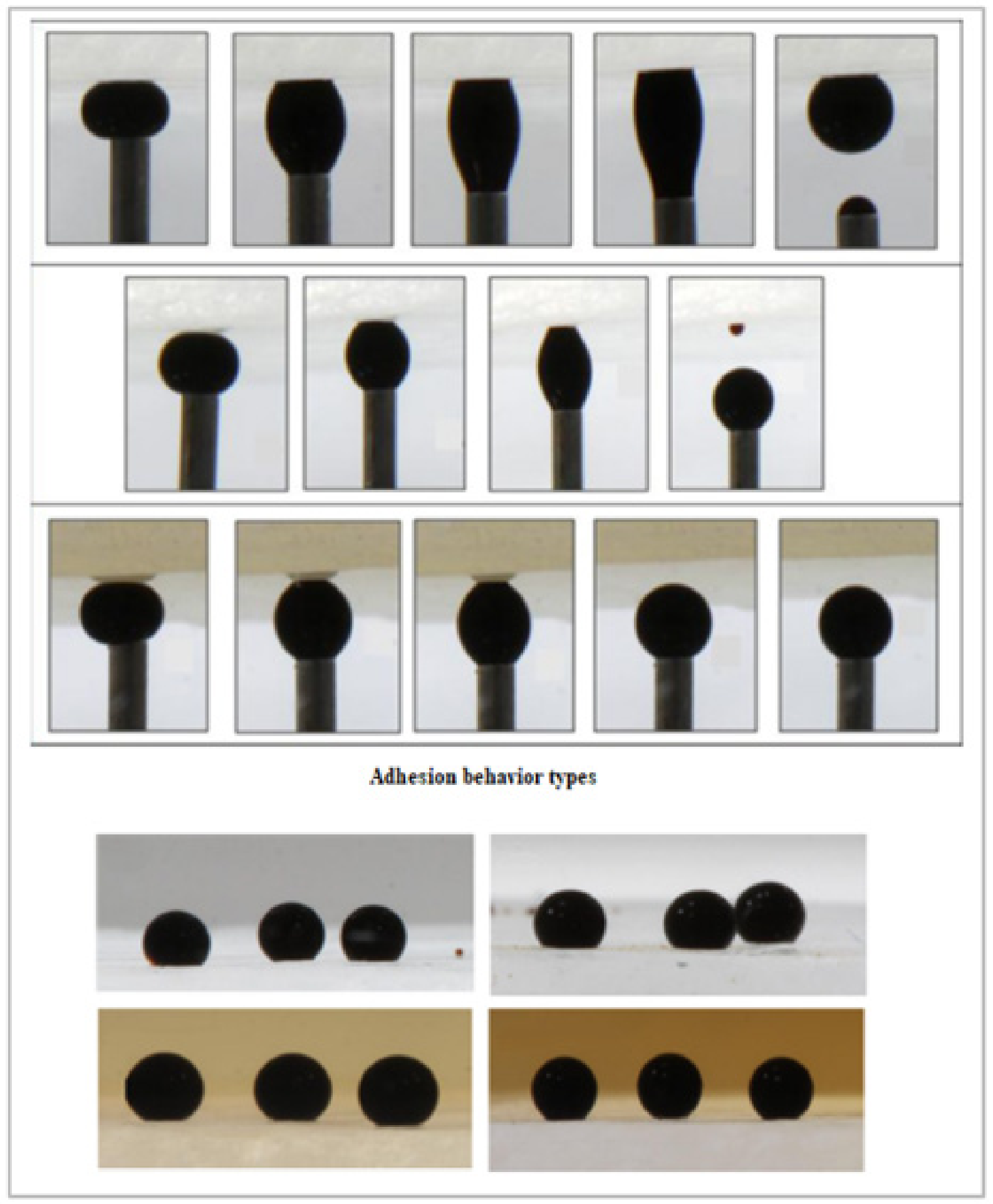

Figure 1: Impact of enzymes on wettability represented by shape of the oil drops (after [9]). 

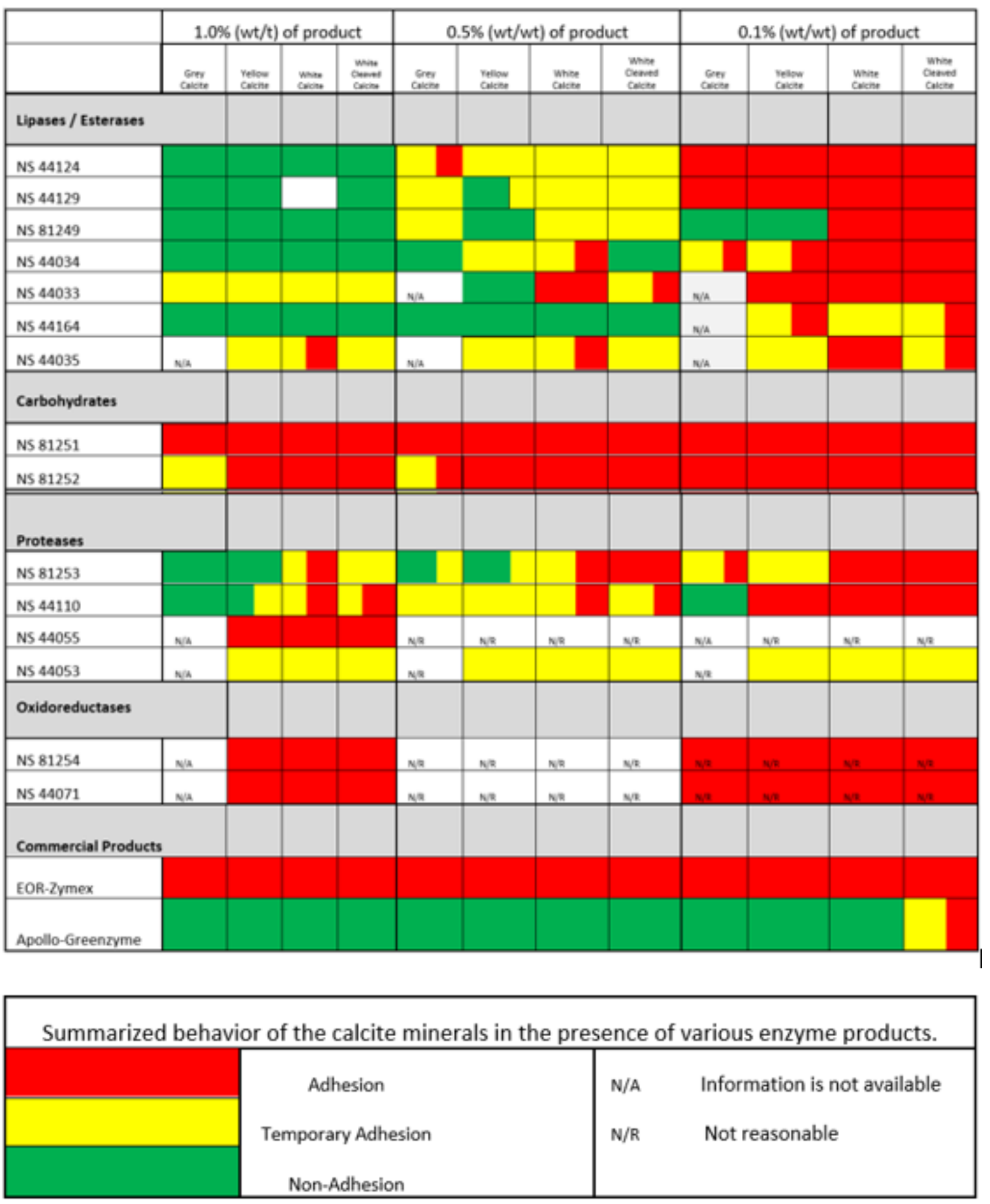

Figure 2: Impact of enzyme classes on adhesion (after [9]).

Experiments of enzyme fluid injection have been performed on various oil fields around the world, with different results. Most studies have shown positive effects on oil production, while some show marginal change. These include fields of various reservoir characteristics such as those in the Anacacho limestone of Texas, USA [24], La Salina of Venezuela [31], Mann Field of Myanmar [25], as well as various other fields in Siberia and China, to name a few [22-23].
Laboratory tests seem to indicate a problem with enzymes in some reservoir pores, particularly in carbonaceous limestone [13]. Experiments done on enzyme solutions flowing through core samples of these reservoirs indicate a possible strong or perhaps permanent adherence of the enzyme to the surface of the rock. If this is the case, it could be assumed that carbonaceous limestone is not a good candidate for EEOR, but research in this area is still lacking and serious conclusions about the mechanisms is to be 
confirmed with more research.

\section{Enzymatic Catalysis Applications}

Mechanisms of paraffin reduction via enzymatic catalysis are not well understood, but theories exist which show some possibility of wax precipitation reduction and cloud point modification by enzymes [13]. Implementation of enzymes that break down long alkane/cycloalkane chains are of interest in this regard. Acinetobacter sp. $6 \mathrm{~A} 2$ is an enzyme that degrades $\mathrm{C}_{10}-\mathrm{C}_{40}$ hydrocarbons, although studies on its use in a practical sense are lacking [26]. Khusainova's study contained early testing of the catalytic properties of esterase enzymes and their potential for changing the chemical composition of oil molecules and their functional groups, as well as the possibility of acid generation and salinity changes which could affect the contact angles of droplets, but also the general stability of the solvation properties in solution [9].

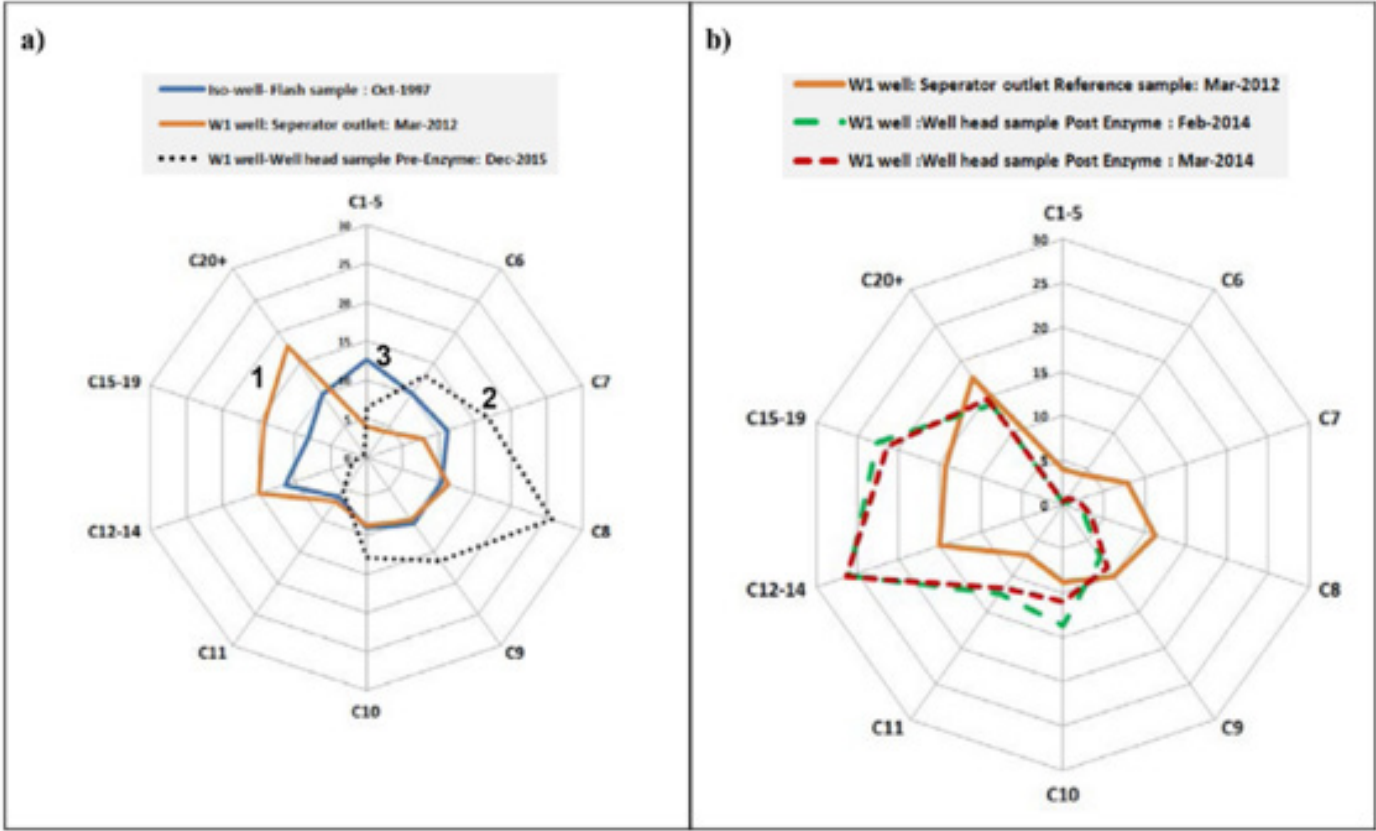

Figure 3: Enzyme enhanced W1 production with more heavy components (after [27]).

The first commercial enzyme treatment in the Middle East was conducted in an offshore carbonate well in the United Arab Emirates (UAE) [27]. Mixed results were observed. Among the 4 treated wells, Well 1 (W1) showed 25\% increase in oil production and sustained for 5 months, with 1550 barrels of incremental oil recovery. In addition to the increased oil production rate, the chemical compositions of the extra produced oil were changed: more heavy components, $\mathrm{C}_{10}-\mathrm{C}_{40}$ and $\mathrm{C}_{12}-\mathrm{C}_{19}$, were produced after EEOR operation (Figure 3). Comparing to W1, W2 and W3 showed no improvements in oil production, with some negative impact on existing gas lift operations in W2. W4 showed a spike of increase in liquid and oil rate. The spike did not sustain. A closer look at the wells indicated that W1 and W4 were producing from permeable reservoirs while W2 and W3 from tight formations. Considering that this treatment was conducted without pre-treatment study due to short notice for operational/schedule reason, overall performance could be considered as positive and promising; and experience and lessons, if any, from this field operation provided valuable guidance for future enzyme EOR application in this region [27].
Enzymatic breakdown of heavy oils into lighter chain, lower specific gravity oil phases is still in its infancy, partially due to limited knowledge of hydrocarbon metabolic pathways that occur in nature. Biotechnology is making headway in the field of novel protein design and modification (Figure 4), which could prove to be revolutionary for EEOR as well as the refinement process downstream of production (Figure 3). Enzymes have been used for the breakdown and cleaning of filter cakes in situations where polymer and starch are included in drilling muds. Results have been both visually and quantitatively positive. Study shows that $\alpha$-amylase and endoglucanase perform extremely well in both field and laboratory environments for the breakdown of starch and xanthan gum buildup that characterizes these filter cakes. Filtercake cleanup and maintenance potentially ensure a variety of smooth drilling and avoid reservoir damage [28-29]. By modifying the structure of the active site (dark spot, Figure 4 left), it is possible that the efficiency and width of applicability of enzyme degradation could be improved greatly (Figure 4). 


\section{Green Enzyme for EOR}

As discussed in the previous section, the 3-dimensional structure of the enzyme provide possibilities of modifying it to enhance its functionality [32]. Green enzyme, i.e., GreenZyme ${ }^{\mathrm{TM}}$, is such a modified product. It is a water-based, inert, enzyme concentrate made from DNA of oil eating microbes. It facilitates the completion of biological reactions affecting polar and viscous forces reducing interfacial tension (IFT) while changing the wettability of the formation. Since its invention, green enzyme has been used to: (1) improve existing oil well production, (2) increase ultimate recovery factor, and (3) extend production life of an oil field. It has also been used for cleaning contaminated sites.

GreenZyme $^{\mathrm{TM}}$ is a line of specially formulated mixtures for commercial treatments of oil wells, among other applications. As with all enzyme treatment goals, GreenZyme ${ }^{\mathrm{TM}}$ is used primarily for the wettability modifications and interfacial tension reduction [30]. It has also been shown to be most effective in wells that have received other enhance oil recovery methods prior to its injection.

In 2000, La Salina Oil Field, located around Lake Maracaibo,
Venezuela, had many blocked, underperforming wells. Well TJ1319 was chosen to receive multiple treatments of GreenZyme ${ }^{\mathrm{TM}}$ for EOR and to test whether the recovery factor would increase after each treatment. GreenZyme ${ }^{\mathrm{TM}}$ had already established success in single treatment applications, but prior to Well TJ-1319 pilot, no multiple treatment applications of a single well with GreenZymeTM had been recorded in South America. After each treatment, initial fluid production increased with produced water being extracted first, followed by increased oil production (Figure 5). Treatments effectively removed near wellbore water blockage for improved permeability. Increased recovery was maintained above the baseline as long as $12+$ months, before starting to decline. GreenZyme ${ }^{\mathrm{TM}}$ was found to be effective in any type of oil environment (heavy, medium, light). Multiple applications of GreenZyme ${ }^{\mathrm{TM}}$ yielded significant increases in production following each treatment, with no negative effects. Over a 16-year span, Well TJ1319 received 6 applications of GreenZyme ${ }^{\mathrm{TM}}$. Each time TJ1319 was treated with GreenZyme ${ }^{\mathrm{TM}}$ it yielded an increase in oil production rate. The first 5 treatments saw a daily average production increase of $335 \%$, and a total of 608,000 barrels of additional oil recovered in the first 8 years [31].

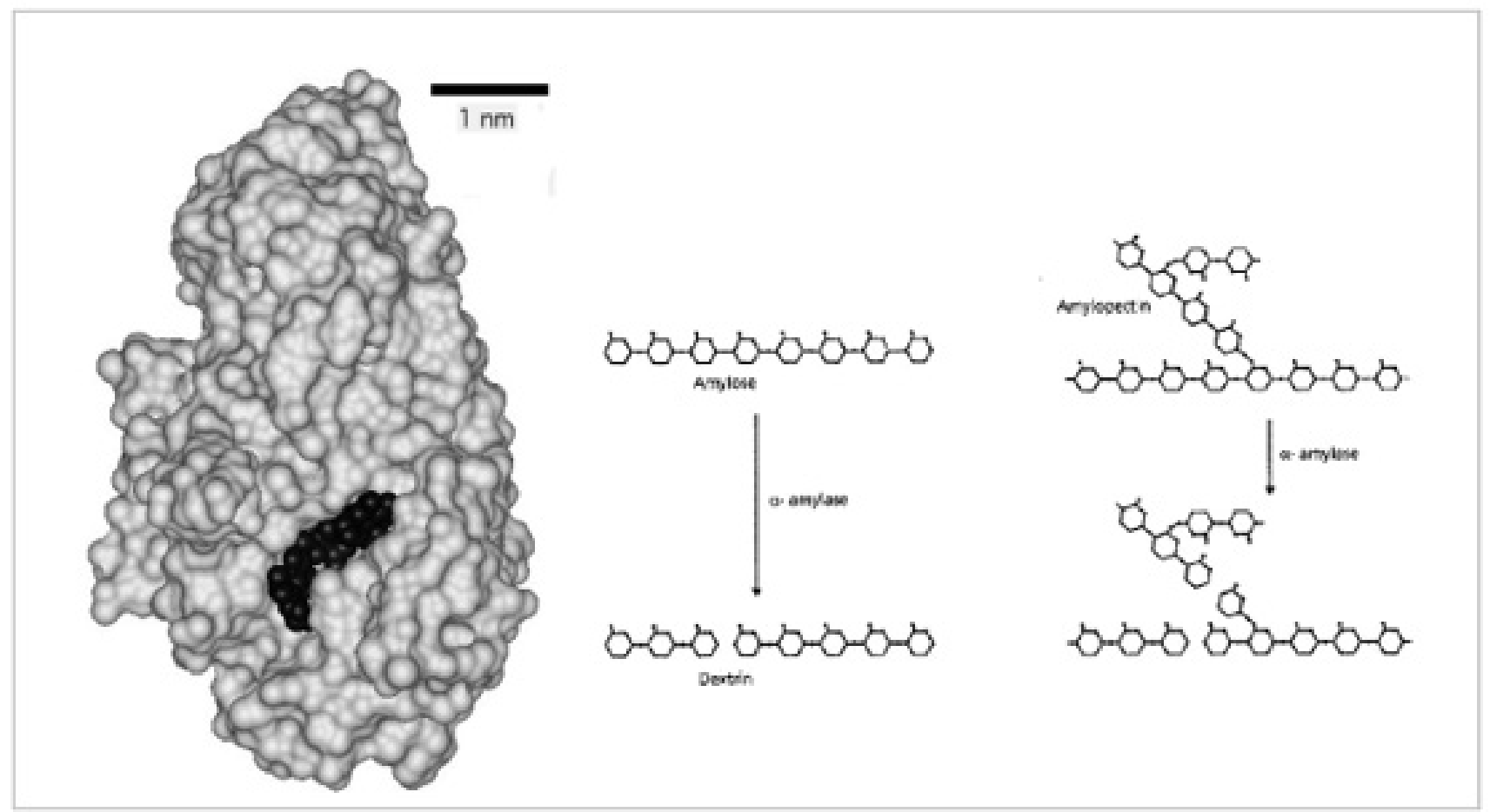

Figure 4: Left- Three-dimensional structure of enzyme (light gray) and substrate (dark) complex for a-amylase and five monomer units of a starch polysaccharide. Right - Reaction mechanism for degradation of amylose and amylopectin to oligosaccharides by a-amylase after being captured in the active site (dark area on left) (after [28]).

Multiple mechanisms for GreenZyme ${ }^{\mathrm{TM}}$ have been proposed in its improving oil production in La Salina Oil Filed, Venezuela [31] and other places [25], as illustrated in Figure 6. In oil-wetted reservoir (carbonate rock), GreenZyme ${ }^{\mathrm{TM}}$ molecules selectively break the oil molecules into smaller droplets (breaking the chains), making the smaller oil droplets easier to flow. In water-wetted reservoir (sandstones), GreenZyme ${ }^{\mathrm{TM}}$ molecules displace oil molecules, and thus increase the recovery factor (Figure 6). 


\section{CASESTUDY \\ VENEZUELA}

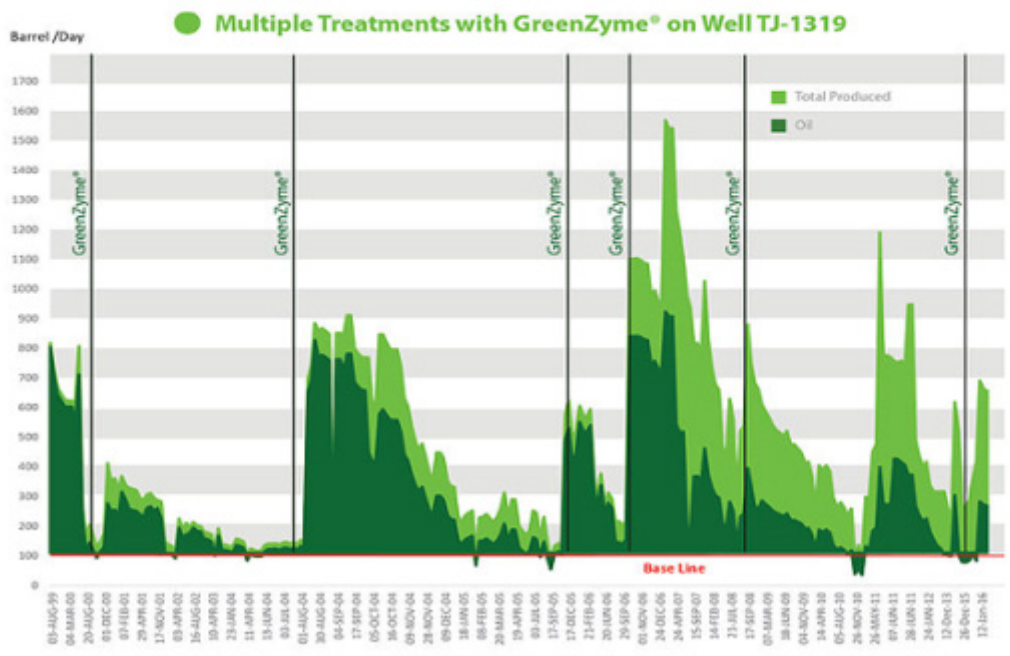

TREATMENTS WITH Greenzyme*

Figure 5: Boost of oil production by GreenZyme ${ }^{\mathrm{TM}}$ in La Salina Oil Field, Venezuela (after [31]).

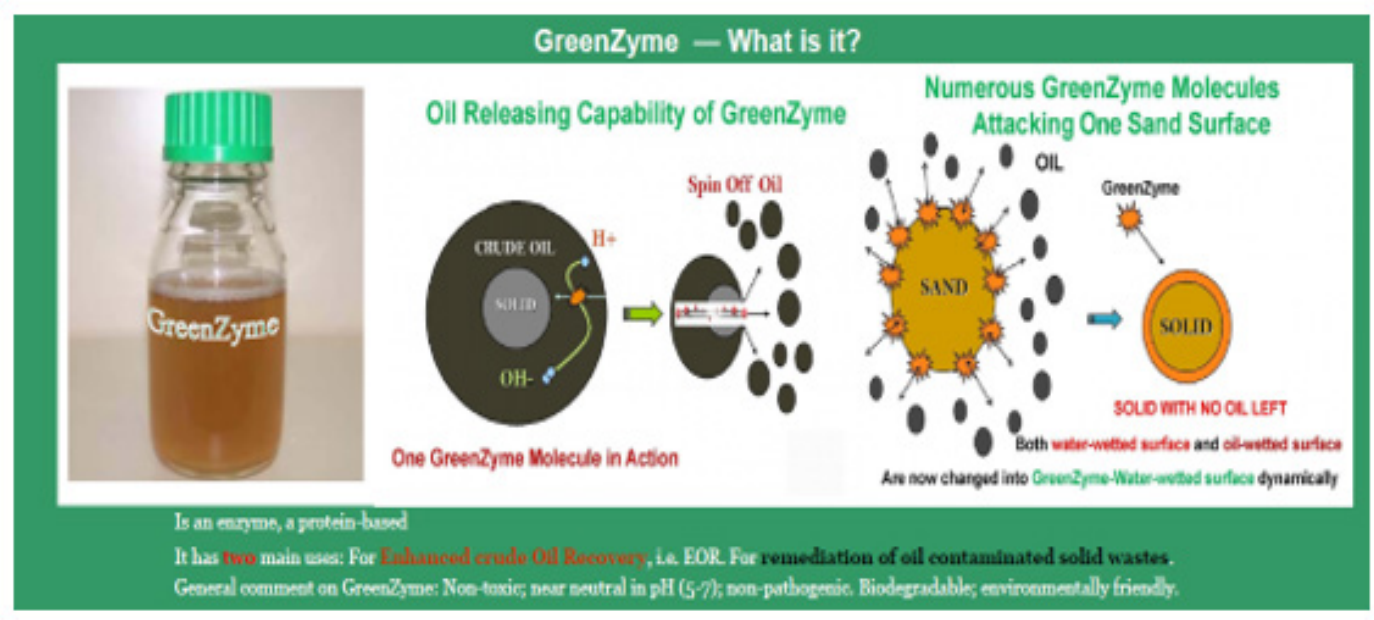

Figure 6: Illustration of Greenzyme mechanisms (after [25]).

\section{Conclusions}

- $\quad$ EEOR has seen significant changes, improvements and research activities in recent years. The primary mechanism for its implementation continues to be wettability modification.

- $\quad$ EEOR has its limitations and challenges. In addition to the limited research, applications, and publication, not every oil well is a good candidate. Pre-treatment study is critical.

- Gas wells, or wells that are producing a significant fraction of gas, have shown poor results in GreenZyme ${ }^{\mathrm{TM}}$ treatments.
- Wells with high water cuts (> 80\%) are also not advisable, as they lead to a much higher loss of injected enzyme out of the wellbore due to increased solubility of the enzyme and less wettability interaction.

- $\quad$ Studies suggest that EEOR is more successful in wells with certain mineral characteristic, particular those of calcite. Tight formation imposes more restrictions to EEOR. More research is needed.

- With the increased data and cases from lab and field 
projects, more efforts are required to digest details of reservoir conditions, and their impact on the EEOR performance, with the ultimate goal of establishing quantitative correlations, for reservoir modeling.

- Due to its interdisciplinary feature, EEOR project will be better conducted via collaborations among experts in biotechnology, chemistry, geology and petroleum engineering.

\section{Acknowledgments}

This study is funded by UT STARs program (Project P501123623) of University of Texas System, Texas, USA. The work received support of data and technical information from one of University of Texas Permian Basin (UTPB) industrial partners, MadMackenzie Solutions, Missouri City, Texas, USA. Mr. Preston Laney, Volunteer Research Assistant of UTPB Petroleum Research Lab in Fall 2019 and undergraduate student in Biology at Arizona State University, helped screen collected data and technical information. All the support and contributions are highly appreciated.

\section{Conflict of Interest}

No conflict of interest.

\section{References}

1. Lake L, Johns RT, Rossen WR, Pope GA (2014) Fundamentals of Enhanced Oil Recovery. Society of Petroleum Engineers, Richardson, Texas, USA $1-17$.

2. Taber JJ, Martin FD, Seright RS (1997) EOR Screening Criteria Revisited - Part 1: Introduction to Screening Criteria and Enhanced Recovery Field Projects. SPE Res Eng 12: 189-198.

3. Alfarge D, Wei M, Bai B (2020) Fundamentals of Enhanced Oil Recovery Methods for Unconventional Oil Reservoirs, Elsevier, Cambridge, Massachusetts, USA.

4. Green DW, Willhite GP (2018) Enhanced Oil Recovery. Society of Petroleum Engineers, Richardson, Texas, USA. 1-14.

5. Sheng J (2013) Enhanced Oil Recovery Field Case Studies. Elsevier-Gulf Professional Publishing, Waltham, Massachusetts, USA.

6. Feng QX, Ma XP, Zhou LH, Shao DB, Wang XL, Qin BY (2009) EOR Pilot Tests With Modified Enzyme-Dagang Oilfield, China. SPE Reservoir Evaluation \& Engineering 12(01): 79-87.

7. Samuel M, Mohsen AH, Ejan AB, Ooi YS, Ashraf S, Nasr-El-Din HA (2010) A Novel a-Amylase Enzyme Stabilizer for Application at High Temperatures. SPE Prod \& Oper 25: 398-408.

8. Oberoi HS, Babbar N, Dhaliwal SS, Kaur S, Vadlani PV, et al. (2012) Enhanced Oil Recovery by Pre-treatment of Mustard Seeds Using Crude Enzyme Extract Obtained from Mixed-Culture Solid-State Fermentation of Kinnow (Citrus reticulata) Waste and Wheat Bran. Food Bioprocess Technol 5: 759-767.

9. Khusainova A, Nielsena SM,Pedersen HH, Woodley JM, Shapiro A (2015) Study of wettability of calcite surfaces using oil-brine-enzyme systems for enhanced oil recovery applications. J Petroleum Sci and Engg 127: 53-64.

10. Zhang JH, Xue QH, Gao H, Ma X, Wang P (2016) Degradation of crude oil by fungal enzyme preparations from Aspergillus spp. for potential use in enhanced oil recovery. J Chem Technol Biotechnol 1: 865-875.

11. Aurepatipan N, Champreda V, Kanokratan P, Chitov T, Bovonsombut $S$ (2018) Assessment of bacterial communities and activities of thermotolerant enzymes produced by bacteria indigenous to oil-bearing sandstone cores for potential application in EOR J Petrol Sci \& Eng 163 : 295-302.

12. Kumagai PS, Gutierrez RF, Lopes JLS, Martins JM, Jameson DM, et al (2018) Characterization of esterase activity from an Acetomicrobium hydrogeniformans enzyme with high structural stability in extreme conditions. Extremophiles 22: 781-793

13. Laney P, Zeng Z (2020) Enzyme Enhanced Oil Recovery: A Current Review of the Technology. PENG Research Lab Report. University of Texas Permian Basin, Midland, Texas, USA. 1-10.

14. Willhite, GP (1986) Waterflooding. Society of Petroleum Engineers, Richardson, Texas, USA. 5-52.

15. Economides MJ, Hill AD, Ehlig-Economides C, Zhu D (2013) Petroleum Production Systems (2nd ed.), Prentice Hall, Upper Saddle River NJ. 299 363.

16. Zeng Z, Grigg RB, Bai B (2006) Experimental development of adsorption and desorption kinetics of a $\mathrm{CO}_{2}$-foaming surfactant onto Berea sandstone. Paper SPE-103117 presented at the SPE Annual Technical Conference, San Antonio, Texas, USA

17. Zitha P, Felder R, Zornes D, Brown K, Mohanty K (2021) Increasing Hydrocarbon Recovery Factors, SPE White Paper, Society of Petroleum Engineers, Richardson, Texas, USA.

18. Grigg RB, Svec RK, Zeng Z, Bai B, Bethapudi LB, Ganda S, Gupta DB, Liu $\mathrm{Y}$ (2003) Improving $\mathrm{CO}_{2}$ Efficiency for Recovering Oil in Heterogeneous Reservoirs. US DOE Technical Report.

19. Lake L (1989) Enhanced Oil Recovery. Prentice Hall, Upper Saddle River, New Jersey, USA. 1-42.

20. El-hoshoudy AN (2019) Application of proteins in enhanced oil recovery-a review. Petroleum and Coal 61(6): 1268 - 1281.

21. Udoh TH, Evangelista L (2020) Potentials of Enzyme Enhanced Oil Recovery - A Review. Petroleum Science and Engineering. 4(2): 51-63.

22. Harris RE, McKay ID (1998) New Applications for Enzymes in Oil and Gas Production. Paper SPE-50621 presented at the European Petroleum Conference, The Hague, Netherlands.

23. Wang Y, Kantzas A, Li B, Li Z, Wang Q, et al. (2008) New Agent for Formation-Damage Mitigation in Heavy-Oil Reservoir: Mechanism and Application. Paper SPE-112355 presented at the SPE International Symposium and Exhibition on Formation Damage Control, Lafayette, Louisiana, USA, February 2008.

24. Gray JL (2007) Analysis of EEOR Using Greenzyme® for Prue Ranch (Anacacho) Oilfield, Hitzfelder \#3 Lease. Technical Report, Jumpstart Energy Services LLC, Houston, TX, USA.

25. Ott WK, Nyo T, Aung WN, Khaing AT (2011) EEOR success in Mann Field, Myanmar.Paper SPE-144231 presented at the SPE Enhanced Oil Recovery Conference, Kuala Lumpur, Malaysia.

26. Jain T, Sharma A (2012) New frontiers in EOR methodologies by application of eEnzymes. Paper SPE-154690 presented at the SPE EOR Conference at Oil and Gas West Asia, Muscat, Oman.

27. Jabbar M, Omar A, Maxime B, Blondeau C, Omar AA (2015) Application of enzyme EOR in a mature UAE offshore carbonate oil field. Paper SPE177688 presented at the Abu Dhabi International Petroleum Exhibition and Conference, Abu Dhabi, UAE

28. Hanssen JE, Jiang P, Pedersen HH, Jørgensen JF (1999) New enzyme process for downhole cleanup of reservoir drilling fluid filtercake. Paper SPE-50709 presented at the SPE International Symposium on Oilfield Chemistry, Houston, Texas.

29. Al-Otaibi MB, Nasr El Din HA, Siddiqui MA (2004) Chemical treatments to enhance productivity of horizontal and multilateral wells: lab studies and case histories. Paper SPE-89467 presented at the SPE/DOE Symposium on Improved Oil Recovery, Tulsa, Oklahoma.

30. Haastrup B (2014) Enzyme penetration tests on carbonaceous rocks for application to enhanced oil recovery. Paper SPE-173461 presented at 
the SPE Annual Technical Conference and Exhibition, Amsterdam, The Netherlands.

31. BTP (2016) Improved Oil Recovery Using GreenZyme - Venezuela Case Study. Technical Report, Biotech Processing Supply LLC, Dallas, Texas, USA.
32. Suzuki H (2020) How Enzymes Work? Jenny Stanford Publishing, Singapore. 87-227. 